\title{
Narrative review of the role of bronchoscopy in airway complications after lung transplantation
}

\author{
Alfredo Jalilie ${ }^{1,2,3 \wedge}$ \\ ${ }^{1}$ Department of Respiratory Diseases and Interventional Bronchoscopy, Clínica Santa María, Santiago de Chile, Chile; ${ }^{2}$ Bronchoscopy Unit, Instituto \\ Nacional del Tórax, Santiago de Chile, Chile; ${ }^{3}$ Universidad de Chile, Santiago de Chile, Chile \\ Correspondence to: Alfredo Jalilie, MD. Av Santa María 0500, Providencia, Santiago de Chile 7520378, Chile. Email: ajalilie@clinicasantamaria.cl.
}

\begin{abstract}
Airway complications following lung transplantation are associated with significant morbidity and mortality. Risk factors associated with airway complications are donor and recipient characteristics, prolonged hypoperfusion, right-side anastomoses, organ preservation, mechanical ventilation, primary graft dysfunction, microbiologic contamination, immunosuppression and acute cellular rejection. Bronchoscopy evaluation has an important role in diagnosis and treatment. Surveillance bronchoscopy control is controversial; however it may be important to evaluate for the early detection of acute rejection and infections. Common airway complications following lung transplantation are classified as early or late complications. Anastomosis or bronchial stenosis, necrosis, bronchial dehiscence, anastomotic infection, post-transplant bronchomalacia, excessive granulation tissue and bronchial fistula, are frequent complications. Stenosis of short or long bronchial extensions is the most frequent complication after three months of transplantation. The impact is greater in cases of mono pulmonary transplants, where the functional capacity is dramatically impaired. This article summarizes the most common post lung transplant complications and the role of bronchoscopy for their identification and management, that includes surveillance, balloon bronchial dilation, ablative therapies and stent placement. Literature shows important evidence for the usefulness of different bronchoscopic methods in the management of complications following lung transplantation, but more research is needed to define the best treatment choice for each lung transplant condition.
\end{abstract}

Keywords: Lung transplantation; interventional bronchoscopy; stent; bronchial stenosis; airway dehiscence

Received: 09 October 2020; Accepted: 18 June 2021; Published: 25 November 2021.

doi: $10.21037 /$ ccts-20-167

View this article at: https://dx.doi.org/10.21037/ccts-20-167

\section{Introduction}

Since the first description of bronchoscopy by Gustav Killian in 1897, the rigid bronchoscope in 1904 by Chavaler Jackson, and the subsequent creation of the flexible bronchoscope by Sigeto Ikeda in 1967, the development and usefulness of this procedure has been gaining importance for airway evaluation and treatment. After James Hardy performed the first human lung transplant in 1963, airway complication had significant morbidity and mortality.

Evaluation of anastomotic technique, advances in organ preservation optimization, improved donor-recipient matching and medical management have led significant reduction in acute airway injury (1).

Thus, in patients undergoing lung transplantation, bronchoscopic surveillance and diagnosis of post-transplant airway complications are essential to both recognize the damage and establish treatment $(2,3)$. Lung transplantation is a procedure associated with significant morbidity, especially during the healing process of bronchial anastomoses, where ischemic circulatory phenomena play an important role in the development of stenosis or dehiscence of the affected tissue (4). Improved surgical techniques

^ ORCID: 0000-0002-8872-6636. 
Table 1 Lung transplant complication classification

Early complications
Bronchial necrosis
Bronchial dehiscence
Anastomotic infection
Late complications
Bronchial stenosis
Post-transplant bronchomalacia
Bronchial fistula
Exophytic excessive granulation tissue formation

have reduced these complications, however, according to the series studied, the incidence of post-transplant airway complications is reported between $4 \%$ and $33 \%(5,6)$. Others risk factors associated with airway complications are donor and recipient characteristics, prolonged hypoperfusion, right-side anastomoses, organ preservation, mechanical ventilation, primary graft dysfunction, microbiologic contamination, immunosuppression and acute cellular rejection (1). Chronic lung allograft dysfunction is a major limitation in long-term survival and affects approximately $75 \%$ of lung transplant recipients within the first 10 years. Infections and acute rejection represent the major problems affecting nearly $30 \%$ of patients. There are basically two modalities of surveillance transplants patients: systematic bronchoscopy for identification and control of acute rejection and asymptomatic airway complications or bronchoscopy performed by acute rejection according to clinical findings. The first is based on the fact that some episodes of acute rejection and infections, particularly cytomegalovirus, are asymptomatic and have a longterm impact on graft viability. However, the literature is controversial as to the superiority of one modality $v s$. the other and the decision seems to lie with the experience of the transplant center (7). In our center, we performer surveillance bronchoscopy every 3 months in the first year of lung transplant and include transbronchial biopsy and bronchoalveolar lavage in order to detect early rejection, silent airway complications or infections that may impact pulmonary function and the impaired of the transplanted patient survival.

This review aims to show the importance of bronchoscopy for the identification and subsequent management of complications according to the international literature.

\section{Types of complications in the airway}

At least four classification systems have been published for post-transplant airway complications, though none of them has been widely accepted. In 2014, Dutau et al. proposed the MDS system to classify central airway complications. The macroscopic appearance of the airway $(M)$, its diameter (D) and the anastomosis suture line (S) were evaluated (8). However, a practical criterion to classify them is by occurrence time: early (less than 3 months) or late (greater than 3 months) (Table 1).

In early complications, necrosis and dehiscence occur more frequently due to perioperative bronchial ischemia. On the other hand, late complications are characterized by stenosis and/or bronchomalacia. These bronchoscopic findings have different degrees of extension, leading to decreased lung function or increasing the risk of bronchial or pulmonary infections (9).

\section{Necrosis and debiscence}

Separation of the surgical anastomosis caused by tissue necrosis constitutes an anastomotic dehiscence (10). Although most patients develop some degree of necrosis, only a fraction of the anastomosis become dehiscent, increasing morbidity and mortality. The estimated incidence of clinically relevant dehiscence is approximately $2 \%$ (11). Risk factors associated with this complication are related to the time of bronchial ischemia, the use of high dose corticoids before and after transplantation, acute rejection, immunosuppression and infection. The clinical presentation is variable and depends on the severity of the dehiscence, detected a few weeks after lung transplant and manifested with sepsis, weaning failure, pneumothorax or persistent air leak. Radiology study with chest computed tomography (chest CT), can help in the diagnosis. However, bronchoscopic evaluation is essential for identifying the complication and its severity (12) (Figure 1). Treatment will depend on the symptoms and severity of the dehiscence. In general, in cases of mild dehiscence, without clinical repercussion, bronchoscopic follow-up is important together with antibiotic treatment. More extensive necrosis may be treated by placement of a covered or uncovered self-expanding metallic stent (SEMS) during flexible fiberoptic of preferably rigid bronchoscopy. SEMS should be left in place, promoting granulation tissue for 6 weeks. The patient is scheduled afterwards for careful removal.

Surgical intervention for severe dehiscence may be 


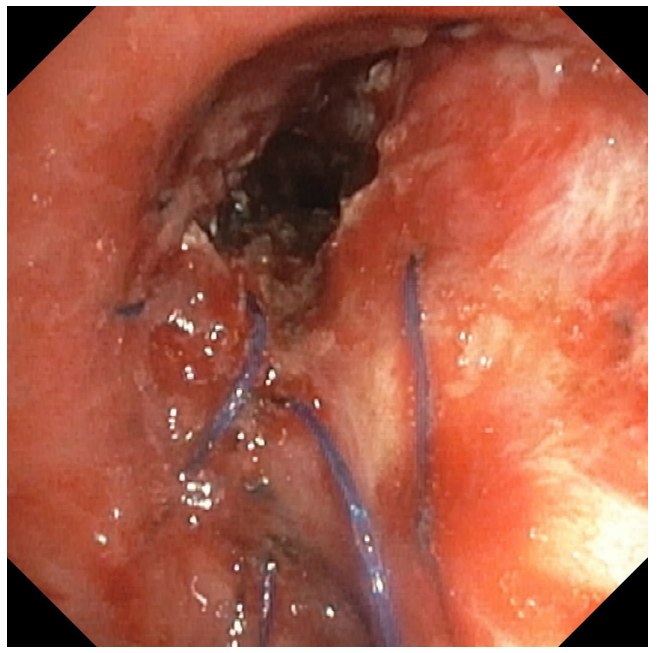

Figure 1 Partial bronchial dehiscence 1 month post-lung transplant.

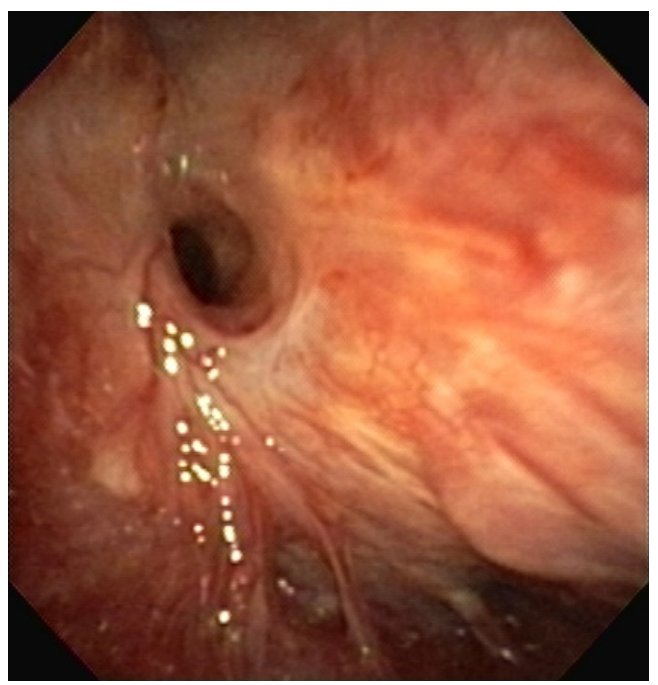

Figure 2 Bronchial stenosis 4 months post-lung transplant.

required if bronchoscopic treatments are not effective. Common surgical treatments for severe dehiscence include open repair for re-anastomosis, flap bronchoplasty, transplant pneumonectomy, or re-transplantation $(12,13)$.

\section{Anastomotic infection}

The use of immunosuppressive therapy associated with tissue injury damaging lymphatic drainage increases the risk of infection in transplanted patients. Colonization and fungal infection of the anastomoses has been reported in $15 \%$ to $35 \%$ of transplant patients, especially by Candida species and Aspergillus species (14). Fever, cough, hemoptysis, wheezing, and spirometric changes can occur due to anastomotic infection.

Bronchoscopy is the standard procedure for microbiological study of secretion and identifying the affected tissue, to establish adequate and opportune treatment.

\section{Bronchial stenosis}

Stenosis of short or long bronchial extensions is the most frequent complication after three months of transplantation. The impact is greater in cases of mono pulmonary transplants, where the functional capacity is dramatically impaired. These complications are mainly caused by ischemia, since the perfusion of the donor bronchus depends on the pulmonary circulation through the bronchial arteries that are generally not revascularized during surgery. Central airway obstructions that required intervention is not a risk factor for the development of bronchiolitis obliterans syndrome or worse overall survival (15).

The incidence of perianastomotic stenosis is reported as $12-40 \%$ and non-anastomotic distal bronchial stenosis as $2-4 \%(6,16)$. Only select patients benefit from stent placement for airways stenosis after lung transplant. Complications related to stent placement are common. Patients with airway complications treated with airway stents undergo a high volume of repeat procedures (17).

Upon clinical suspicion, radiological and bronchoscopic evaluation may well define the location, extent and degree of loss of diameter of the affected bronchial lumen (Figure 2).

The intermedius bronchus is the most frequent site of non-anastomotic stenosis. Severe symptomatic narrowing can develop, critically reducing its lumen. This is the vanishing bronchus intermedius syndrome (VBIS) (Figure 3). This condition can impair the patient's survival and affect post-transplant quality of life (18).

Post-transplant bronchial stenosis management, should contemplate restoration of the bronchial lumen in order to maintain it over time. It implies repeated bronchoscopic procedures. There are non-permanent therapeutic methods such as balloon bronchial dilations associated in some cases with thermal ablative procedures such as neodymium-doped Yttrium aluminum garnet (Nd: YAG) laser, electrocautery or Argon plasma coagulation (APC). Also, cryoablation therapy is useful. In general, balloon dilation is the initial treatment for the management of bronchial stenosis and can be resolved through this route. However, complex 


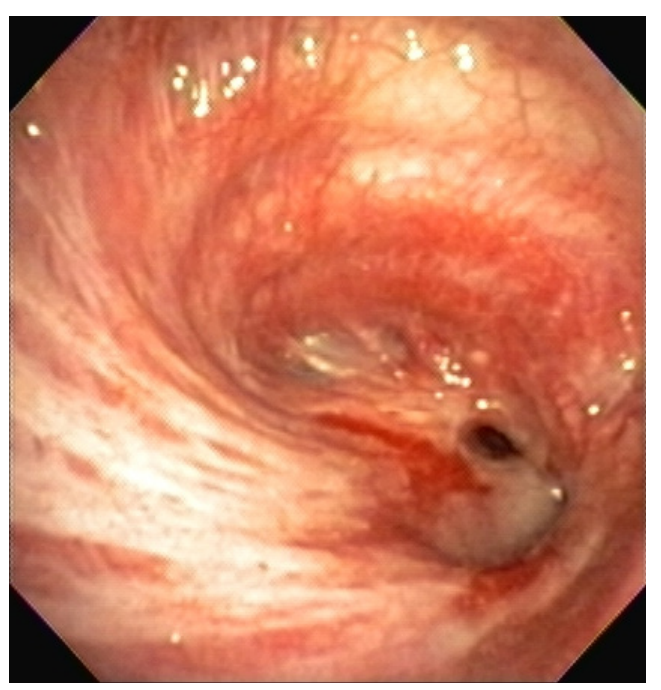

Figure 3 Vanishing bronchus intermedius syndrome, 6 months post-lung transplant.

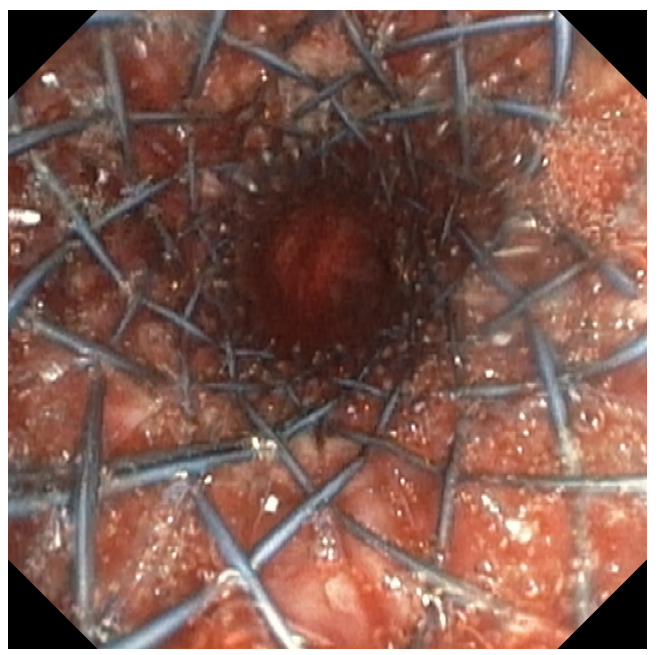

Figure 4 Covered self-expanding metallic stent in main left bronchus stenosis, 6 months post-lung transplant.

stenosis refractory to treatment with balloon dilations must be managed with more permanent methods such as the placement of bronchial stents (19). Experience with stenting has changed over time. The most commonly used stents are SEMS predominantly made of nitinol. On other hand, temporary use of silicone stents in this context is efficient but also associated with higher complication rates, likely because of longer survival, but also more complex anatomy and thus poor congruence, favoring migration and mucus plugging (20). SEMS can be covered or uncovered and placed with flexible bronchoscopy and conscious sedation, unlike silicone stents that require general anesthesia and rigid bronchoscopy for installation. Most published series have shown experience with covered SEMS with less incidence of complications in relation to granulation tissue generation and stent migration $(19,21)$ (Figure 4).

In recent years, the development of biodegradable stents has been an alternative treatment for stenosis with the possibility of definitive treatment $(21,22)$. Bronchoscopic surveillance should be systematic in the follow-up of bronchial stenosis whether treated by balloon dilation, ablative methods or stents. Another type of therapy is systemic and topical medication. Mitomycin-C is an anti-fibrotic agent and has been used in post-transplant bronchial stenosis. Some case studies suggest that it may be useful (23).

\section{Post-transplant bronchomalacia}

Bronchomalacia is a dynamic obstructive phenomenon that occurs during expiration and produces many degrees of obstruction, generally greater than $50 \%$ of the bronchial lumen. They can also be associated with bronchial stenosis, further impairment lung function in patients, decrease clearance of secretions and increasing risk of infections (24). Bronchoscopy is the choice diagnostic method for direct visualization of the dynamic obstructive phenomenon (Figure 5).

Management is aimed at improving secretion clearance by supporting kinesiotherapy, mucolytic therapy and in some cases, non-invasive positive pressure ventilation use. Clinically symptomatic bronchomalacia may benefit from stenting. The experiences reported with silicone stents for 6 to 12 months to promote airway remodeling with subsequent removal, have had a good response (25).

\section{Bronchial fistulae}

Bronchial fistulas in the post-transplant period represent a serious complication, but are infrequent. The bronchial defect may have communication with the mediastinum, pleural space or vasculature. Prolonged bronchial ischemia and fungal infections are very important risk factors for its appearance. The presence of bronchial fistulas can be presented with symptoms of sepsis, massive hemoptysis, pneumothorax, pneumomediastinum, subcutaneous emphysema and persistent air leak (26,27). Bronchoscopy can demonstrate bronchial defect, with the support of 


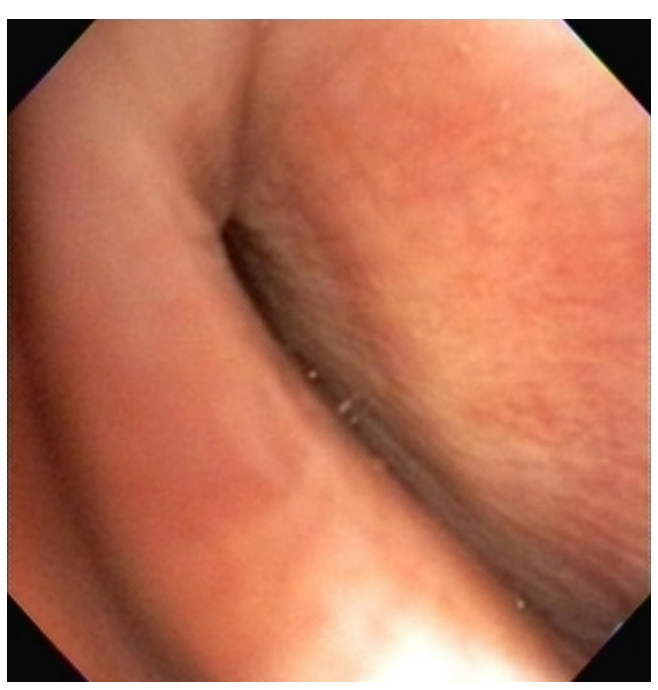

Figure 5 Bronchomalacia, 4 months post-lung transplant.

chest CT images. Closing communication is the objective of treatment. Surgical approach is an option for chronic or large fistulas. Bronchoscopic management is the best treatment for small fistulas with a short time of evolution. The use of fibrin derivatives or uncovered SEMS are alternative treatment (13).

\section{Granulation tissue formation}

Airway obstruction by excessive granulation tissue in posttransplant patients is a common complication. Up to $20 \%$ of patients present this complication (28).

Tissue injury and the associated inflammatory process are probably the main causes; however, fungal colonization has also been associated with excessive granulation tissue formation (29).

Symptoms of obstructive granulation tissue may include dyspnea, cough, post-obstructive pneumonia, hemoptysis, and difficulty clearing secretions (6).

Treatment depends on the presence of an obstructive or non-obstructive component in bronchoscopy evaluation. Mechanical debridement via flexible forceps is the elective procedure. Small non-obstructing lesions may be debulked with forceps using flexible bronchoscopy or using the beveled edge of a rigid bronchoscope (30).

In otherwise, ablative therapies are necessary like $\mathrm{Nd}$ : YAG laser, electrocautery or APC. Cryotherapy can be effective in extensive debridement to restore patency of the airway with less bronchial or anastomotic trauma (31). Photodynamic therapy has also been reported but should be used with extreme caution as serious complications, including fatal hemoptysis $(32,33)$.

\section{Summary}

Bronchoscopy is a fundamental identification and management tool of airway post-lung transplant complications that represents quality of life impairment of the transplanted patient. Although the incidence of post-lung transplant complications is low, delay in their identification and treatment, represents a significant morbidity and mortality for patients. Literature shows important evidence for the usefulness of different bronchoscopic methods in the management of complications following lung transplantation, but more research is needed to define the best treatment choice for each lung transplant condition.

\section{Acknowledgments}

I would like to thank the team of nurses and medical technologists of bronchoscopy units from Clinica Santa Maria and Instituto Nacional del Tórax for their contribution to this manuscript.

Funding: None.

\section{Footnote}

Peer Review File: Available at https://ccts.amegroups.com/ article/view/10.21037/ccts-20-167/prf

Conflicts of Interest: The author has completed the ICMJE uniform disclosure form (available at https://ccts. amegroups.com/article/view/10.21037/ccts-20-167/coif). The author has no conflicts of interest to declare.

Ethical Statement: The author is accountable for all aspects of the work in ensuring that questions related to the accuracy or integrity of any part of the work are appropriately investigated and resolved.

Open Access Statement: This is an Open Access article distributed in accordance with the Creative Commons Attribution-NonCommercial-NoDerivs 4.0 International License (CC BY-NC-ND 4.0), which permits the noncommercial replication and distribution of the article with the strict proviso that no changes or edits are made and the original work is properly cited (including links to both the formal publication through the relevant DOI and the license). 
See: https://creativecommons.org/licenses/by-nc-nd/4.0/.

\section{References}

1. Crespo MM, McCarthy DP, Hopkins PM, et al. ISHLT Consensus Statement on adult and pediatric airway complications after lung transplantation: Definitions, grading system, and therapeutics. J Heart Lung Transplant 2018;37:548-63.

2. Paradis TJ, Dixon J, Tieu BH. The role of bronchoscopy in the diagnosis of airway disease. J Thorac Dis 2016;8:3826-37.

3. Glanville AR. The role of surveillance bronchoscopy post-lung transplantation. Semin Respir Crit Care Med 2013;34:414-20.

4. Hyytinen TA, Heikkilä LJ, Verkkala KA, et al. Bronchial artery revascularization improves tracheal anastomotic healing after lung transplantation. Scand Cardiovasc J 2000;34:213-8.

5. Santacruz JF, Mehta AC. Airway complications and management after lung transplantation: ischemia, dehiscence, and stenosis. Proc Am Thorac Soc 2009;6:79-93.

6. Alvarez A, Algar J, Santos F, et al. Airway complications after lung transplantation: a review of 151 anastomoses. Eur J Cardiothorac Surg 2001;19:381-7.

7. Frye BC, Gasplmayr M, Hettich I, et al. Surveillance Bronchoscopy for the Care of Lung Transplant Recipients: A Retrospective Single Center Analysis. Transplant Proc 2021;53:265-72.

8. Dutau H, Vandemoortele T, Laroumagne $\mathrm{S}$, et al. A new endoscopic standardized grading system for macroscopic central airway complications following lung transplantation: the MDS classification. Eur J Cardiothorac Surg 2014;45:e33-8.

9. Frye L, Phillips EK. Management of airway complications following lung transplantation. Shanghai Chest 2020;4:28.

10. Weder W, Inci I, Korom S, et al. Airway complications after lung transplantation: risk factors, prevention and outcome. Eur J Cardiothorac Surg 2009;35:293-8; discussion 298.

11. Mughal MM, Gildea TR, Murthy S, et al. Short-term deployment of self-expanding metallic stents facilitates healing of bronchial dehiscence. Am J Respir Crit Care Med 2005;172:768-71.

12. Kroegel C, Hekmat K, Möser A, et al. Airway complications following lung transplantation - clinic, diagnosis, and interventional management. Pneumologie
2011;65:293-307.

13. Mahajan AK, Khandhar SJ. Treatment of airway complications following lung transplantation. AME Med J 2019;4:13.

14. Solé A, Salavert M. Fungal infections after lung transplantation. Transplant Rev (Orlando) 2008;22:89-104.

15. Shofer SL, Wahidi MM, Davis WA, et al. Significance of and risk factors for the development of central airway stenosis after lung transplantation. Am J Transplant 2013;13:383-9.

16. Sonett JR, Conte JV, Orens J, et al. Removal and repositioning of "permanent" expandable wire stents in bronchial airway stenosis after lung transplantation. J Heart Lung Transplant 1998;17:328-30.

17. Ma KC, Li M, Haas AR, et al. Efficacy and safety of airway stenting to treat anastomotic complications after lung transplant: a cohort study. J Thorac Dis 2020;12:3539-48.

18. Shah S, Karna D, Minai O, et al. Symptomatic narrowing or atresia of bronchus intermedius following lung transplantation vanishing bronchus intermedius syndrome (VBIS). Chest 2006;130:236S.

19. Saad CP, Ghamande SA, Minai OA, et al. The role of selfexpandable metallic stents for the treatment of airway complications after lung transplantation. Transplantation 2003;75:1532-8.

20. Guibert N, Saka H, Dutau H. Airway stenting: Technological advancements and its role in interventional pulmonology. Respirology 2020;25:953-62.

21. Thistlethwaite PA, Yung G, Kemp A, et al. Airway stenoses after lung transplantation: incidence, management, and outcome. J Thorac Cardiovasc Surg 2008;136:1569-75.

22. Lischke R, Pozniak J, Vondrys D, et al. Novel biodegradable stents in the treatment of bronchial stenosis after lung transplantation. Eur J Cardiothorac Surg 2011;40:619-24.

23. Oliveira HG, Oliveira DM, Greggianin C, et al. Biodegradable stent in a patient with recurrent stenosis after lung transplantation. J Bras Pneumol 2019;45:e20190078.

24. Davidson KR, Elmasri M, Wahidi MM, et al. Management of Lung Transplant Bronchial Stenosis With Mitomycin C. J Bronchology Interv Pulmonol 2019;26:124-8.

25. Ridge CA, O'donnell CR, Lee EY, et al.

Tracheobronchomalacia: current concepts and controversies. J Thorac Imaging 2011;26:278-89.

26. Carden KA, Ernst A. Management of Tracheobronchomalacia. In: Simoff MJ, Sterman DH, Ernst A. editors. Thoracic Endoscopy: Advances in Interventional 
Pulmonology. Wiley-Blackwell, 2008:344-51.

27. Hoff SJ, Johnson JE, Frist WH. Aortobronchial fistula after unilateral lung transplantation. Ann Thorac Surg 1993;56:1402-3.

28. Argento AC, Wolfe CR, Wahidi MM, et al. Bronchomediastinal fistula caused by endobronchial aspergilloma. Ann Am Thorac Soc 2015;12:91-5.

29. Tendulkar RD, Fleming PA, Reddy CA, et al. High-doserate endobronchial brachytherapy for recurrent airway obstruction from hyperplastic granulation tissue. Int J Radiat Oncol Biol Phys 2008;70:701-6.

30. Pasqualotto AC, Denning DW. Post-operative

doi: $10.21037 /$ ccts-20-167

Cite this article as: Jalilie A. Narrative review of the role of bronchoscopy in airway complications after lung transplantation. Curr Chall Thorac Surg 2021;3:36. aspergillosis. Clin Microbiol Infect 2006;12:1060-76.

31. Mahajan AK, Folch E, Khandhar SJ, et al. The Diagnosis and Management of Airway Complications Following Lung Transplantation. Chest 2017;152:627-38.

32. DiBardino DM, Lanfranco AR, Haas AR. Bronchoscopic Cryotherapy. Clinical Applications of the Cryoprobe, Cryospray, and Cryoadhesion. Ann Am Thorac Soc 2016;13:1405-15.

33. Hara R, Itami J, Aruga T, et al. Risk factors for massive hemoptysis after endobronchial brachytherapy in patients with tracheobronchial malignancies. Cancer 2001;92:2623-7. 